\title{
Challenges and opportunities for monitoring wild Nile crocodiles with scute mark-recapture photography
}

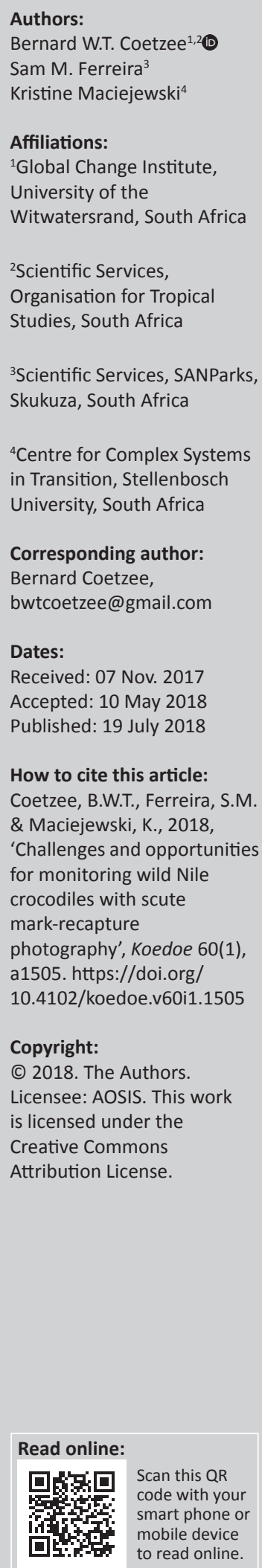

The global conservation status of Nile crocodiles (Crocodylus niloticus) was last assessed in 1996. The species presents particular difficulty in monitoring because it can be cryptic, require expertise to handle, and caudal tail tags and transmitters are often lost. Some studies advocate mark-recapture techniques based on photograph identification of the unique scute markings of crocodile tails as a non-invasive means of monitoring their populations. Researchers developed this method with crocodiles in captivity. In this study, we test the technique under field conditions by monitoring crocodiles from 2015 to 2017 in the Sunset Dam in the Kruger National Park. Using a Cormack-Jolly-Seber open population model, we found that the dam may host 15-30 individuals, but that there is a high turnover of individuals and much uncertainty in model outputs. The dam's population thus has high rates of immigration and emigration. The method proved challenging under field conditions, as there was bias in identifying scute markings consistently. The efficient use of the method requires an exceptional quality of photographic equipment. Animal crypsis, however, remains an issue. In this study, we discuss how to improve the mark-recapture photography methodology, especially to adapt the technique for citizen science initiatives.

Conservation implications: Using scute mark-recapture photography presents challenges under field conditions. These challenges require innovative, practical and analytical solutions to successfully use the technique before monitoring programmes, aimed at ensuring the persistence of crocodiles in the wild, can be implemented.

\section{Introduction}

The Nile crocodile, Crocodylus niloticus, is an apex predator and keystone species across Africa (Ashton 2010). It serves as an indicator species and populations are proxies for aquatic ecosystem health (Ashton 2010). The current global conservation status of the Nile crocodile, as assessed by the International Union for Conservation of Nature (IUCN), is Least Concern, but the species was previously listed as Vulnerable from 1982 to 1990 (IUCN 2017) and is listed as Vulnerable under the South African Red List assessment (Marais 2014). Even so, recent declines in crocodile populations recorded across several rivers and lakes, with particularly marked declines in the Olifants Gorge within the Kruger National Park (Ferreira \& Pienaar 2011), raise conservation concerns. Consequently, there is a need to ascertain the conservation status of Nile crocodile populations. This relies on efficient monitoring techniques.

Nile crocodiles present particular challenges for monitoring, especially over large spatial areas. Aerial surveys are useful for counting crocodiles, but consistently yield lower estimates than spotlight surveys at night (Combrink et al. 2011; Ferreira \& Pienaar 2011), especially for smaller size classes. Crocodiles can be cryptic, which reduces their detectability (Thomas et al. 2010). Capture mark-recapture studies rely on individually marked crocodiles using scute-removal techniques or the attachment of numbered plastic tags on their tails, or VHF (very high frequency) transmitters (Bourquin 2007; Leslie 1997). The capturing of crocodiles, however, can be challenging, as the signal of VHF transmitters is often difficult to detect owing to thick vegetation; it is also time-consuming, expensive and dependent on individual behaviour that may vary (Bourquin \& Leslie 2011). These may also bias the re-catchability of certain sexes, sizes or age classes (Bayliss et al. 1987). This is not only as a result of improper signal detection from VHF transmitters but also because of the plastic caudal tags, often cattle ear tags, which fail when they fall off, reducing the robustness of mark-recapture estimates (Bourquin 2007; Swanepoel 1999).

In addition, methods employed to monitor key species may have negative impacts on the welfare of individuals as well as species persistence. The fitment of devices on birds, for instance, has significant effects on energy expenditure, nesting likelihood (Barron et al. 2010) and population 
dynamics (Saraux et al. 2011). Ethical considerations should be a key element of biological monitoring designs (Putman 1995), which require the development of less invasive monitoring techniques.

Researchers have advocated a scute identification technique to better monitor crocodile populations (Bouwman \& Cronje 2016; Swanepoel 1996). It is less invasive, less time-consuming and potentially more accurate. The scute markings on the tail provide a unique identification for each crocodile, allowing comparisons between individuals in a population. This method does not require the capture of an animal, but observers need to positively identify an individual visually or through the use of photography. Using mark-recapture photography, the method may 'capture' a portion of a population with photographs, and identify and catalogue unique markings. Then the proportion of 'marked' individuals recaptured in subsequent photographic sampling events allows the estimation of population sizes (Bouwman \& Cronje 2016). This approach has potential use for population monitoring, research and application for citizen science initiatives aimed at monitoring individuals in the wild (Bouwman \& Cronje 2016).

The development of the mark-recapture photography techniques, however, focused on captive crocodiles (Bouwman \& Cronje 2016; Swanepoel 1996). Identifying animals in captivity enables researchers to handle specimens, which allows for clearly identified scute markings, removing any issues with regard to individual detectability. Here, we develop and test a monitoring protocol by assessing the suitability of mark-recapture photography for crocodiles under typical field conditions. Our first aim is to use the technique to calculate the population size and monitor crocodiles at a single dam in the Kruger National Park. Our second aim is to report on the challenges and opportunities with this approach. This allows us to better guide the use of such techniques when operationalised under field conditions. To test the potential role of citizen scientists in such initiatives, we conducted our study at a popular tourist site, at a dam frequented by crocodiles. Our study thus also replicated techniques with equipment that we considered tourists might typically employ and in conditions they might face.

\section{Methods}

\section{Study site and methods}

This study took place over two years at Sunset Dam $\left(25^{\circ} 06.972^{\prime} \mathrm{S} 031^{\circ} 54.729^{\prime} \mathrm{E}\right)$ near the Lower Sabie rest camp in the Kruger National Park. Sunset Dam is $200 \mathrm{~m}$ from the Sabie River. Tourists have regular sightings of crocodiles at this dam.

Our sampling focused on four events of three days each during April 2015, February 2016, September 2016 and February 2017. Sampling at the study site was only conducted when heavy wind, rain or overcast conditions were absent. Each sampling event consisted of counting crocodiles from a game drive vehicle parked at Sunset Dam. Observers counted crocodiles every $30 \mathrm{~min}$, starting at 09:00 and ending at 12:00, noting all visible crocodiles on land and in the water at the time. When visible, observers also photographed the tails of all crocodiles for later individual identification using the scute marking technique (details follow). To emulate the equipment that tourists might use, we used a combination of photography techniques including a DSLR (75-300 mm lens DSLR Canon ELS Rebel T3I camera), a Canon H50 Powershot with $50 \times$ digital zoom and 'digiscoping' by taking photographs through a Nikon ED field spotting-scope, mounted on a tripod inside the vehicle. During the first sampling event (April 2015), observers also measured the distance to all crocodiles, noted from the observation point with a laser range finder (Foresty $5506 \times 21)$.

The distinct markings on scutes running laterally down the tail allows the individual identification of Nile crocodiles (Bouwman \& Cronje 2016; Swanepoel 1996). We applied Swanepoel's (1996) method, although subsequent work suggests an alternative 11-scute system (see Bouwman \& Cronje 2016). We, however, generated a unique nine-scute code by recording the markings of the last anterior, unfused scute and the subsequent scutes moving towards the head (Figure 1). The code was generated by recording the number of black marks on each scute and the relative position of the scute on which the mark(s) were located. If there were multiple black marks per tail segment, we repeated the corresponding scute number to the number of those marks. Adding parentheses to numbers represented single marks that occasionally extend across different scutes. Square brackets signified marks that are of a lighter colouration.

We created a crocodile photographic database containing either the left or the right scute markings identified during the study. Each record contains a unique ID; an exemplar

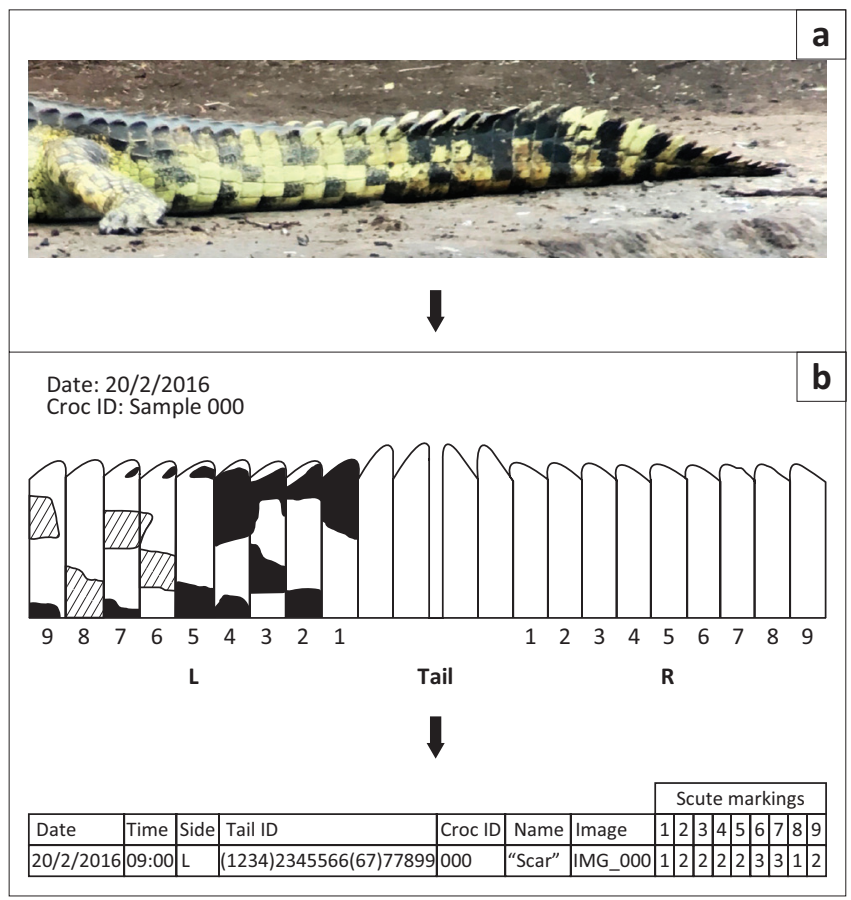

FIGURE 1: Conceptual diagram demonstrating the scute encoding procedure followed, based on photographs of crocodile tail scutes. 
photograph, whether it was the left or right tail observed; and a unique scute marking code, whether it was present or absent during subsequent sampling events. At least four observers captured data from photographs, assigned scute codes by consensus and drew conceptual diagrams of the tails (Figure 1b). Four observers in 2017 set out to test the level of agreement rates between different observers and independently captured data for each newly photographed individual. We considered 'disagreement' between assigned scute codes to be when three or more scute numbers differed from at least two observers among the codes assigned to each crocodile.

\section{Data analysis}

Firstly, we provide summary statistics of the overall crocodile photographic database created during the study period. Then, because it was particularly important to survey crocodiles when they were basking out of the water, and available for photographic mark-recapture, we estimated the change in crocodile abundance over time during the halfhourly sampling periods recorded on both land and in the water.

To estimate the population size in order to determine changes at Sunset Dam in our dataset, we applied markrecapture analysis. For this purpose, we considered individuals with unique left and unique right scute codes as 'marked'. Subsequent photographs and scute codes matched to previously coded individuals were 'recaptured'. We implemented a Cormack-Jolly-Seber (CJS) open population model to calculate the estimated population size (Pledger, Pollock \& Norris 2003). Model implementation in ' $R$ ' (2017) used the package ' $m r a$ ' (Amstrup, McDonald \& Manly 2005) to calculate a population size estimate and standard error. Since crocodiles have different left- and right-hand scute marks (Bouwman \& Cronje 2016; Swanepoel 1996), we ran a 'Left' model (left side of tail photographs only) and a 'Right' model (right side of tail photographs only).

\section{Results}

A total of 113 left and right scute markings made up our sample during 2015-2017. After a total of 36 h of observation, only three individuals had both left- and right-hand sides photographed with certainty (based on visually tracking the individual for changing orientation). Our data comprised a total of 56 left tail and 57 right tail scute markings. The number of crocodiles on land decreased during the morning counts (Figure 2; Pearson's $R=-0.94$; $p<0.01 ; N=7$ ), while those counted in water did not (Figure 2; Pearson's $R=0.65 ; p=0.117 ; N=7$ ). Standard deviation bars, however, overlapped half-hourly, indicating no appreciable peak in numbers of crocodiles basking on land (Figure 2). When comparing individual scute markings, the four observers collecting data during February 2017 disagreed on 8 out of 14 photographs they collected in total, a $57 \%$ disagreement rate. Photographed crocodiles were on average more than $120 \mathrm{~m}$ away (mean $=124 \mathrm{~m}$; $\mathrm{SD}=37.5 \mathrm{~m}$; $N=53)$.

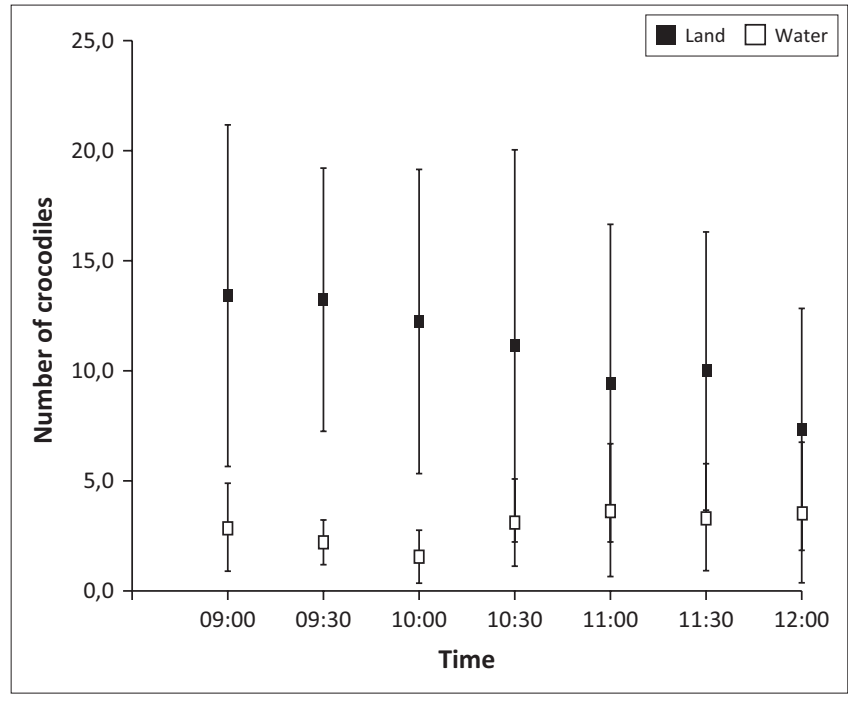

FIGURE 2: Individual counts at half-hourly intervals of four sampling events, during 12 days, of crocodiles seen on land and in the water in and around Sunset Dam at Lower Sabie, Kruger National Park.

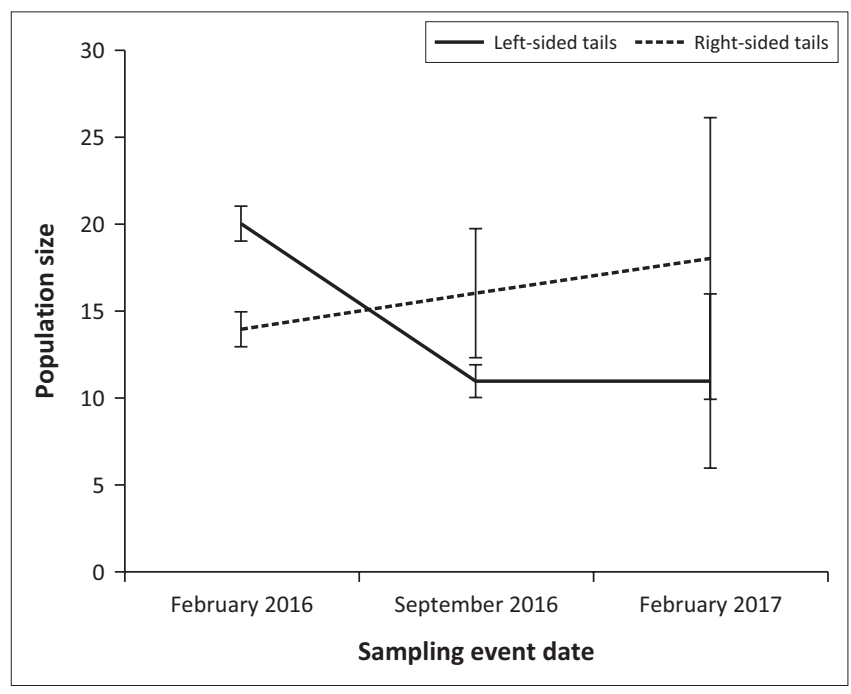

FIGURE 3: Modelled crocodile abundance across three repeat sampling events at Sunset Dam, Lower Sabie, Kruger National Park, using a Cormack-Jolly-Seber mark-recapture analysis. See text for model coefficients.

Overall, there was a low recapture rate. We recaptured only 13 scute markings and no unique scute markings were captured in all four sampling events. Despite the ratio of left to right photographed tails being similar (56 left vs. 57 right), the markrecapture analysis indicated different population size estimates during sampling events, as the analysis is dependent on the accumulating recapture rate. In 2017, which indicates the longest time interval of mark-recapture data, population sizes were 11 $( \pm 5.0 \mathrm{SE})$ and 18 ( $\pm 8.1 \mathrm{SE})$ for the left and right tails, respectively (Figure 3). These modelled population size estimates overlapped with the data obtained from morning counts (see Figure 2). Model fit can be considered robust (Left model: $\mathrm{AIC}=54.17$; Log likelihood $=$-24.08; Deviance $=48.17 ; N=4$ and Right model: AIC $=41.61 ; \log$ likelihood $=-16.80$; Deviance $=33.61 ; N=4$ ).

\section{Discussion}

The crocodile population at the study site is dynamic. Low rates of individual recaptures suggest high rates of movement 
of crocodiles to and from Sunset Dam during the study period. Crocodiles most likely move into and from the nearby Sabie River. Despite this finding, the population model demonstrated a relatively consistent number of crocodiles across years. We infer that $15-30$ crocodiles regularly use the dam.

The low rate of recaptures emphasise that the use of the dam by crocodiles is in flux. The results suggest high levels of emigration and immigration, consistent with observations that crocodiles can move long distances over land. Nile crocodiles in the Kruger National Park moved up to $36 \mathrm{~km}$ along the Olifants River between South Africa and Mozambique (Swanepoel 1999). Fergusson (2010) recorded crocodile movements of up to $90 \mathrm{~km}$. Crocodile movement may be affected by changes in water levels. In the dry season when water levels receded, crocodiles moved from the Ume River towards the Kariba Dam (Games 1990). The same was found in the Amazon Basin with Melanosuchus niger and Caiman crocodylus retreating from the flooded forests in the wet season to the lakes in the dry season (Ron,Vallejo \& Asanza 1998).

The error rates in our modelled population estimates are high, as they cannot account for crocodile tails being obscured from view in the water (which may underestimate numbers), and cannot account for double counting either sides of the same individual (which would overestimate numbers). The development of statistical techniques that accommodate single-side marking and detectability biases can improve the use of unique tail markings to estimate Nile crocodile population sizes. The low recapture rate and difficulties with scute identification using the photographic technique will further increase error in the model.

The present study tested and demonstrated the feasibility of a photographic mark-recapture technique for monitoring Nile crocodiles. However, the method proved challenging under field conditions and for citizen science application. The use of this approach requires addressing three major challenges. Firstly, successful identification relied heavily on the quality of the photographs. Only photographs of exceptional quality were suitable. Slight decreases in image resolution or poor lighting rendered photographs unsuitable. In addition, most images taken in the study were at distances greater than $100 \mathrm{~m}$. Our experience suggests that an SLR camera lens of $500 \mathrm{~mm}$ or greater could produce consistent and reproducible crocodile images.

Secondly, the identification of scute markings was subjective for most photographs, regardless of their quality. The disagreement rate between observers of more than $50 \%$ implies observer difficulty and potentially bias in identifying scute markings from photographs. We attempted to overcome this by determining scute markings by consensus. Although statistical techniques can address observer bias in aerial surveys, for instance (Lubow \& Ransom 2016), such bias is problematic to resolve analytically in our case. We propose the use of paper cards (Figure 1b) to help facilitate identification between observers. Multiple observers classify the scutes independently and then reach the final codes by consensus. The approach thus requires training observers for consistency. We acknowledge that the use of automated picture identification software (e.g. Kuhl \& Burghardt 2013) and machine learning (e.g. Michalski, Carbonell \& Mitchell 2013) could greatly enhance the consistent identification of scute markings.

The third challenge is species crypsis, which alters the detectability of crocodile tails and so reduces the ability to monitor populations effectively (Thomas et al. 2010). Observers can only photograph basking crocodiles. Even if away from the water, debris and mud or the orientation of the individual may obscure tail scutes. Orientation is particularly problematic as scutes differ between the left and right side of the tail, and our results demonstrate that it may alter population estimates. Nile crocodiles may also spend more time out of the water during winter, and therefore sampling may better detect the species during June-July.

While the scute marking method would be appropriate for captured animals, using photography presents challenges under field conditions. These challenges require innovative, practical and analytical solutions to successfully use a photographic mark-recapture method based on scute markings that can inform interventions aimed at ensuring the persistence of crocodiles in the wild.

\section{Acknowledgements}

The authors thank the following observers: Tavis Dalton, Sam Kubica, Olivia Vennaro, Claire Weston, Brian Brooks, Lauren Chang, Catherine Craighill, Tatiana Henry, Katie Diggs, Brianna Mathias, Annie Stevens, Jana Woerner, Joey Binder, Max Israelit, Drew Perlmutter and Henry Stevens. Funding was provided by the Organisation for Tropical Studies, South Africa. H. Coetzee kindly redrew Figure 1.

\section{Competing interests}

The authors declare that they have no financial or personal relationships that may have inappropriately influenced them in writing this article.

\section{Authors' contributions}

K.M. and S.M.F. conceptualised the study. K.M. and B.W.T.C. conducted and coordinated all the fieldwork. B.W.T.C. performed the analysis and wrote the first draft. All the authors contributed to subsequent drafts of this article.

\section{References}

Amstrup, S.C., McDonald, T.L. \& Manly, B.F.J., 2005, Handbook of capture-recapture analysis, Princeton University Press, Princeton, NJ.

Ashton, P.J., 2010, The demise of the Nile crocodile (Crocodylus niloticus) as a keystone species for aquatic ecosystem conservation in South Africa: The case of the Olifants River, CSIR Report, CSIR, Pretoria.

Barron, D.G., Brawn, J.D. \& Weatherhead, P.J., 2010, 'Meta-analysis of transmitter effects on avian behaviour and ecology', Methods in Ecology Evolution 1, 180-187. https://doi.org/10.1111/j.2041-210X.2010.00013.x 
Bayliss, P., 1987, 'Survey methods and monitoring within crocodile management programs', in G.J.W. Webb, S.C. Manolis \& P.J. Whitehead (eds.), Wildlife management: programs', in G.J.W. Webb, S.C. Manolis \& P.J. Whitehead (eds.), Wildlife
Crocodiles and alligators, pp. 157-176, Surrey Beatty and Sons, Sydney.

Bourquin, S.L., 2007, 'The population ecology of the Nile crocodile (Crocodylus niloticus) in the panhandle region of the Okavango Delta, Botswana', PhD thesis, Stellenbosch University, Stellenbosch.

Bourquin, S.L. \& Leslie, A.J., 2011, 'Estimating demographics of the Nile crocodile (Crocodylus niloticus Laurenti) in the panhandle region of the Okavango Delta, Botswana', African Journal of Ecology 50, 1-8. https://doi.org/10.1111/j.13652028.2011.01285.x

Bouwman, H. \& Cronje, E., 2016, 'An 11-digit identification system for individual Nile crocodiles using natural markings', Koedoe 58, 1-6. https://doi.org/10.4102/ koedoe.v58i1.1351

Combrink, X., Korrûbel, J.L., Kyle, R., Taylor, R. \& Ross, P., 2011, 'Evidence of a declining Nile crocodile (Crocodylus niloticus) population at Lake Sibaya, South Africa', South African Journal of Wildlife Research 41, 145-157. https://doi.org/10.3957/056.041.0201

Fergusson, R., 2010, Wildlife survey phase 2 and management of human-wildlife conflicts in Mozambique, Survey of Crocodile Populations in Mozambique, Vol. 2 Part 5, AGRECO G.E.I.E., Brussels, Belgium.

Ferreira, S.M. \& Pienaar, D., 2011, 'Degradation of the crocodile population in the Olifants River Gorge of Kruger National Park, South Africa', Aquatic Conservation 21, 155-164. https://doi.org/10.1002/aqc.1175

Games, I., 1990, 'The feeding ecology of two Nile crocodile populations in the Zambezi Valley', PhD thesis, University of Zimbabwe, Harare.

IUCN, 2017, IUCN Red list: Crocodylus niloticus, viewed 23 October 2017, from http:// www.iucnredlist.org/details/46590/0

Kuhl, H.S. \& Burghardt, T., 2013, 'Animal biometrics: Quantifying and detecting phenotypic appearance', Trends in Ecology and Evolution 28, 432-441. https:// doi.org/10.1016/j.tree.2013.02.013

Leslie, A.J., 1997, 'The ecology and physiology of the Nile crocodile, Crocodylus niloticus', PhD thesis, Drexel University Philadelphia, PA.
Lubow, B.C. \& Ransom, J.I., 2016, 'Practical bias correction in aerial surveys of large mammals: Validation of hybrid double-observer with sightability method against known abundance of feral horse (Equus caballus) populations', PLoS One 11 known abundance of feral horse (Equus caballus) popu
e0154902. https://doi.org/10.1371/journal.pone.0154902

Marais, J., 2014, 'Crocodylus niloticus (Laurenti, 1768)', in M.F. Bates, W.R. Branch, A.M. Bauer, M. Burger, J. Marais, G.J. Alexander et al., (eds.), Atlas and red list of the reptiles of South Africa, Lesotho and Swaziland, Suricata 1, South African National Biodiversity Institute, Pretoria.

Michalski, R.S., Carbonell, J.G. \& Mitchell, T.M., 2013, Machine learning: An artificial intelligence approach, Springer Science \& Business Media, Palo Alto, CA.

Pledger, S., Pollock, K.H. \& Norris, J.L., 2003, 'Open capture-recapture models with heterogeneity: I. Cormack-Jolly-Seber Model', Biometrics 59, 786-794. https:// doi.org/10.1111/j.0006-341X.2003.00092.X

Putman, R.J., 1995, 'Ethical considerations and animal welfare in ecological field studies', Biodiversity and Conservation 4, 903-915. https://doi.org/10.1007/ BF00056197

Ron, S.R., Vallejo, A. \& Asanza, E., 1998, 'Human influence on the wariness of Melanosuchus niger and Caiman crocodilus in Cuyabeno, Ecuador', Journal of Herpetology 32, 320. https://doi.org/10.2307/1565444

Saraux, C., Le Bohec, C., Durant, J.M., Viblanc, V.A., Gauthier-Clerc, M., Beaune, D. et al., 2011, 'Reliability of flipper-banded penguins as indicators of climate change', al., 2011, 'Reliability of flipper-banded penguins as indicators
Nature 469, 203-206. https://doi.org/10.1038/nature09630

Swanepoel, D.J.G., 1996, 'Identification of the Nile crocodile Crocodylus niloticus by the use of natural tail marks', Koedoe 39, 113-115. https://doi.org/10.4102/ koedoe.v39i1.287

Swanepoel, D.J.G., 1999, 'Movements, nesting and the effects of pollution on the Nile crocodile Crocodylus niloticus in the Olifants River, Kruger National Park', MSc thesis, University of Natal, Pietermaritzburg.

Thomas, L., Buckland, S.T., Rexstad, E.A., Laake, J.L., Strindberg, S., Hedley, S.L. et al., 2010, 'Distance software: Design and analysis of distance sampling surveys for estimating population size', Journal of Applied Ecology 47, 5-14. https://doi. org/10.1111/j.1365-2664.2009.01737.x 